\title{
Experimental Study on Stability Analysis of a Structure during Excavation beneath This Structure
}

\author{
Yichen Miao, ${ }^{1,2}$ Baoxian Liu, ${ }^{3}$ Changwu Liu $\mathbb{D}^{2,4}{ }^{2}$ Zhile Shu, ${ }^{3}$ and Haikuan $\mathrm{Wu}^{2,4}$ \\ ${ }^{1}$ Institute of Disaster Management and Reconstruction, Sichuan University-The Hong Kong Polytechnic University, \\ Chengdu, China \\ ${ }^{2}$ State Key Laboratory of Hydraulics and Mountain River Engineering, Sichuan University, Chengdu, China \\ ${ }^{3}$ College of Civil Architecture and Environment, Xihua University, Chengdu, China \\ ${ }^{4}$ College of Water Resource and Hydropower, Sichuan University, Chengdu, China
}

Correspondence should be addressed to Changwu Liu; liuchangwu@scu.edu.cn

Received 22 October 2019; Accepted 2 May 2020; Published 29 May 2020

Academic Editor: Emanuele Brunesi

Copyright (C) 2020 Yichen Miao et al. This is an open access article distributed under the Creative Commons Attribution License, which permits unrestricted use, distribution, and reproduction in any medium, provided the original work is properly cited.

In order to create more underground space, it was important to investigate the impact of excavation on the preexisting building. In this paper, a scale model test was conducted to analyze the stability of the structure during excavation. The model consisted of underpinning piles preinstalled in clay, with a reinforced concrete building placed on underpinning piles. The strain and settlement of the structure were observed to reveal the time settlement of columns and the time strain of beams, columns, and piles during excavation. The results showed that the strain change of beams was small, and strain values of columns were getting higher. And underpinning piles had great strain variations. They were of great significance to underpinning design and engineering practice.

\section{Introduction}

During the last few decades, the needs for underground space had raised in downtown. Making the underground space beneath a preexisting building can be an effective solution. Underpinning and excavation would help to expand the underground space without affecting the daily use of the building. Underpinning was a broad term to describe the process of modifying an existing foundation by adding support, which included jet grouting, compaction grouting, and micropiles [1]. Based on scale model test and cases, underground underpinning technology had made progress in Japan [2-4]. Meanwhile, some underpinning methods based on the underground construction were widely adopted in many countries [5-10]. Recently, underpinning technology had achieved rapid development in China [11-14]. Finally, several valuable conclusions of underpinning technology based on scale model experiment were achieved in recent years. Han and Ye systematically investigated the load transfer mechanism during the connection of micropiles to the concrete plate under initial load $[15,16]$. The behavior of underpinning piles was found based on a real case in China, which included axial-loading and excavation-unloading responses of piles [17].

In summary, the design of underpinning mostly relied on the case history, case monitoring, and engineering experience, resulting from the complexity of underpinning and excavation mechanism. Some of the previous researches were about monitoring data in cases. And others focused on the load transfer mechanism of piles during underpinning and excavation. Systematically investigating the behavior of piles and the preexisting structure in cases might bring up several unsolvable problems during excavation. Similarly, based on the existing mechanism of underpinning pile, many complicate engineering phenomena cannot be explained. Finally, the scale modeling might help to analyze 
this engineering problem, but most of the scale model tests only focused on the influence of adjacent buildings during excavation [18-21].

In this paper, a small-scale indoor physical model test was conducted to simulate the underpinning and excavation beneath the preexisting foundation. And micropiles were applied to support the upper structure. The excavation procedure was carefully monitored. And observations included columns settlement, and strain changes of columns, beams, and piles. This offered an opportunity to study the stability of the preexisting structure and the behavior of micropiles as a result of soil stress relief. The paper focused on strain changes of the preexisting structure and vertical displacements of columns during excavation.

\section{Scale Model Test Setup}

Taking the difficulty and cost of the test into account, a small-scale model test was proposed to conduct the underpinning and excavation test, using the scale of $1: 10$, which is shown in Figure 1.

The whole small-scale physical model included two parts: an upper frame structure and a lower soil-micropile model.

The upper frame structure was cast in situ, and the model materials consisted of the fine wire and the particulate concrete. The structure model had 4 layers without floor and had a length of $1130 \mathrm{~mm}$ with a width of $980 \mathrm{~mm}$. And the structure height above the foundation head was $1500 \mathrm{~mm}$. The first layer was $600 \mathrm{~mm}$ high (including $100 \mathrm{~mm}$ embedding depth of foundation), and the second to the fourth layers were all $300 \mathrm{~mm}$ high. The section of each column was $50 \times 50 \mathrm{~mm}$, and the section size of each beam was $30 \times 60 \mathrm{~mm}$. The height of each spread footing was $60 \mathrm{~mm}$, the section size was $230 \times 230 \mathrm{~mm}$, four holes were reserved for each independent footing, and the diameter of each hole was $32 \mathrm{~mm}$. A load of $640 \mathrm{~N}$ was applied to each layer except the first layer to simulate the daily use of the building. Material parameters are shown in Table 1.

The lower soil-micropile model included four parts: soil material, micropiles, the settlement model box, and the diaphragm wall. Soil material was local clay in Chengdu, which had some typical geological conditions. Chengdu clay was distributed in a large area on the plane from the eastern suburbs of Chengdu to the foot of Longquan Mountain. It varied, but there were no obvious sedimentary discontinuities in the vertical section, with $2 \mathrm{~m}$ to $7 \mathrm{~m}$ in thick in general. And the clay was composed of a set of red-yellow clay, which was roughly divided into three layers from top to bottom, according to the color of the soil, layer, the degree of fissure development, and the differences in inclusions. In Chengdu clay, sand grains accounted for $2 \%$ to $6 \%$, powder grains accounted for $24.5 \%$ to $34.5 \%$, and clay particles accounted for $60.8 \%$ to $73.0 \%$. As for typical engineering properties, in addition to the soil parameters listed in $\mathrm{Ta}-$ ble 2, Chengdu clay is generally free of water and impervious to water. In local fissure development areas, surface water and atmospheric precipitation were easy to infiltrate and recharge, so there was little water content, and the permeability coefficient $K$ was from 0.002 to $0.001 \mathrm{~m} / \mathrm{d}$, which was slightly permeable. And Chengdu clay had a certain swelling property.

In this test, the diameter of soil particle was below $10 \mathrm{~mm}$. The model ground was compacted with the hammer method to compaction. This preparation procedure gave ground dry unit weight of $15.7 \mathrm{kN} / \mathrm{m}^{3}$ (compaction value was $80 \%$ ). It was important to note that the compaction in this was a little far from the compaction in fields, mainly because the underpinning piles were preinstalled in the model box, and excessive force of the hammer might damage the strain gauges on piles. In all model testing the ground density was checked with small cans burred at vertical intervals of $100 \mathrm{~mm}$. The properties of Chengdu clay are shown in Table 2.

In order to simplify the model test, plexiglass rods were used to make the model piles. Based on the local engineering experience and design method [22], there were four underpinning piles under each footing, which had a height of $900 \mathrm{~mm}$ and a diameter of $30 \mathrm{~mm}$.

The model box was constructed of welded steel plates and fortified planks, which were polished and lubricated to decrease the boundary effect $[23,24]$. At the same time, taking the width of settlement influenced zone into consideration, the model box was made of $1900 \mathrm{~mm}$ long and $1900 \mathrm{~mm}$ wide [25]. And based on the depth of settlement influenced zone, it was $1400 \mathrm{~mm}$ high (Chinese pile foundation code).

The support method was the three-sided diaphragm wall for support, without a diaphragm wall on excavation side. A crossbeam was placed at the top of the excavation side to ensure the stability of the original support system. The deflection of the diaphragm wall was not involved in this paper. However, there were some limits in diaphragm wall. Due to the special support structure and the close distance between the wall and the pile, the lateral movement of the diaphragm wall and the pile behavior affected by the lateral movement of the wall might not be ignored, which need to be improved in the future.

The size of model test is shown in Figure 2.

The monitoring system was consisted of strain gauges and dial indicator. Both the instrumentation setup and the number of piles, columns, and beams are shown in Figure 3. In particular, strain gauges of the beams were arranged at the midpoint of the bottom of each beam, and they were totally arranged at the first layer and the second layer of the structure. Similarly, strain gauges of the columns were arranged at midpoint of each column at the first layer.

Once the model test was initiated, some expected difficulties need to be avoided during the procedure of installing micropiles (such as obstacles created by installment space, vibration, and disturbance during installation of micropiles). All micropiles were preinstalled in the model box. They were not connected to the spread footings until the settlement of the superstructure tended to stabilize. Although this setup deviated from real practice, the behavior of the underpinning foundation after connection was still valid. The preinstallation did not cause much interface to the settlement observation; therefore, the installation of micropiles was feasible. 


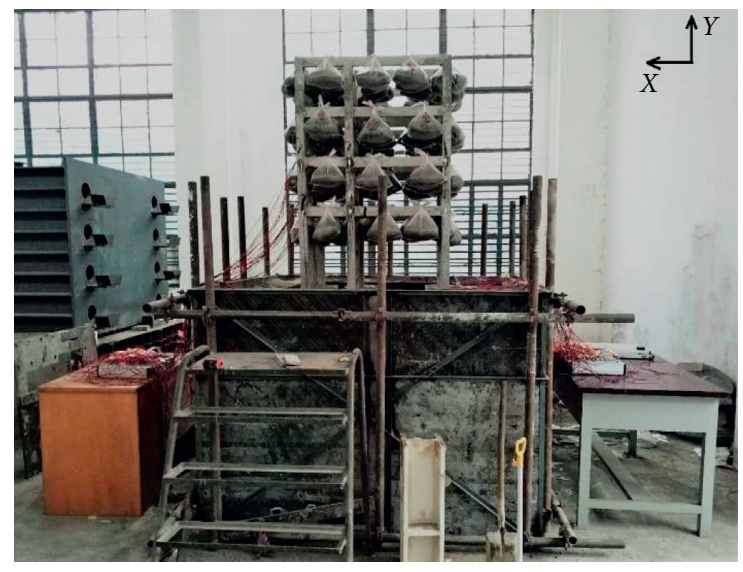

(a)

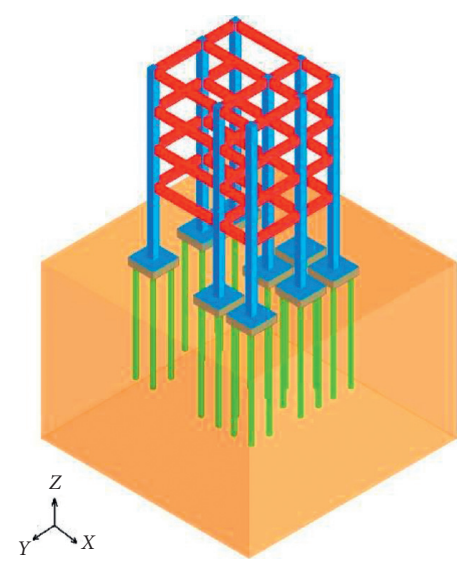

(b)

Figure 1: Model test.

TABLE 1: Material parameters in this test.

\begin{tabular}{lc}
\hline Compressive strength of concrete cubes $(\mathrm{MPa})$ & 14.1 \\
Plexiglass rods' elastic modulus $(\mathrm{MPa})$ & 2700 \\
Model scale & $1 / 10$ \\
Concrete elastic modulus similarity ratio & $1 / 4$ \\
\hline
\end{tabular}

TABLE 2: Parameters of test soil.

\begin{tabular}{lc}
\hline Compressive modulus $(\mathrm{MPa})$ & 6.8 \\
Dry unit weight $\left(\mathrm{kN} / \mathrm{m}^{3}\right)$ & 15.7 \\
Maximum dry unit weight $\left(\mathrm{kN} / \mathrm{m}^{3}\right)$ & 19.5 \\
Moisture content $(\%)$ & 27.3 \\
Internal friction angle $\left(^{\circ}\right)$ & 20 \\
Cohesion $(\mathrm{kPa})$ & 24.7 \\
Shear modulus $(\mathrm{MPa})$ & 1.2 \\
\hline
\end{tabular}

In particular, based on the trial request, the soil was excavated from one side instead of excavating from top to bottom. And soil was excavated by area in order except soil beneath spread footings, which was excavated in the end. The strain monitoring system started to work in Stage III, and it would continue to work for 138 hours. Finally, the excavation sequence is shown in Table 3 , and the number of excavation areas is shown in Figure 4.

The test steps shown in Figure 5 are as follows. (a) Step I: micropiles were preinstalled in the model box. Then, soil was filled into the model box, using tools to compact soil. (b) Step II: the small-scale RC frame structure was uplifted into the model box, ensuring that the four reserved holes of each spread footing were perfectly matched with the preinstalled micropiles. And a load of $640 \mathrm{~N}$ was applied on each layer except for the first layer. After the settlement of the structure tending to be stable, the spread footings and the micropiles were effective connected. (c) Step III: strain monitoring system started to work, and excavation of soil in Areas A and B was finished after 2 hours. (d) Step IV: soil in Areas 3 and $C$ was excavated after 20 hours. (e) Step V: soil in Areas 2, 6, and D was dug away after 25 hours. (f)
Step VI: soil in Areas 1, 5, and 9 was excavated after 42 hours. (g) Step VII: soil in Areas 4 and 8 was dug away after 49 hours. (h) Step VIII: soil in Area 7 was excavated after 67 hours. Meanwhile, a little part of soil surrounding pile group was trimmed carefully because it is beyond the boundary of the spread footing. (i) Step IX: top half of the soil under the foundation was excavated after 73 hours. (j) Step X: rest of the soil under the foundation was dug away after 90 hours. (k) Step XI: the bottom of the excavation was clean and compacted after 114 hours. To ensure the accuracy of the test data, the monitoring data was continued to be obtained for 138 hours.

\section{Strain Changes of Beams}

Strain gauges of beams were arranged at the first layer and the second layer of the structure. Strain data of beams in the first layer were recorded as B1-1 to B1-12. Similarly, strain of beams in the second layer is called B2. And the plus sign indicated axial tension, and the minus sign indicated axial compression.

Figure 6 showed strain changes of beams in the first two layers. Through data analysis, the following rules were obtained. (1) Each excavation caused fluctuations of strain, and the largest changes of strain were from Stage VIII to Stage IX. Mainly because the soil under each spread footing was excavated, the stress from the foundation transferred rapidly to underpinning piles, resulting in the stress redistribution in some beams. (2) The fluctuations of strain in the first layer were much larger than that in the second layer, due to the reason that the stresses of beams in the first layer were larger than that in the second layer. (3) Many fluctuations of strain in beams were low during excavation. It revealed that the strain change of beams was less affected by excavation. But most of the strain values had increased a little in the end, especially in Stage IX. Finally, strain fluctuations of B1-11, B2-4, and B2-12 were larger, partly due to asymmetry of the structure and the method of excavation, which caused the stress concentration in the small part of beams. 


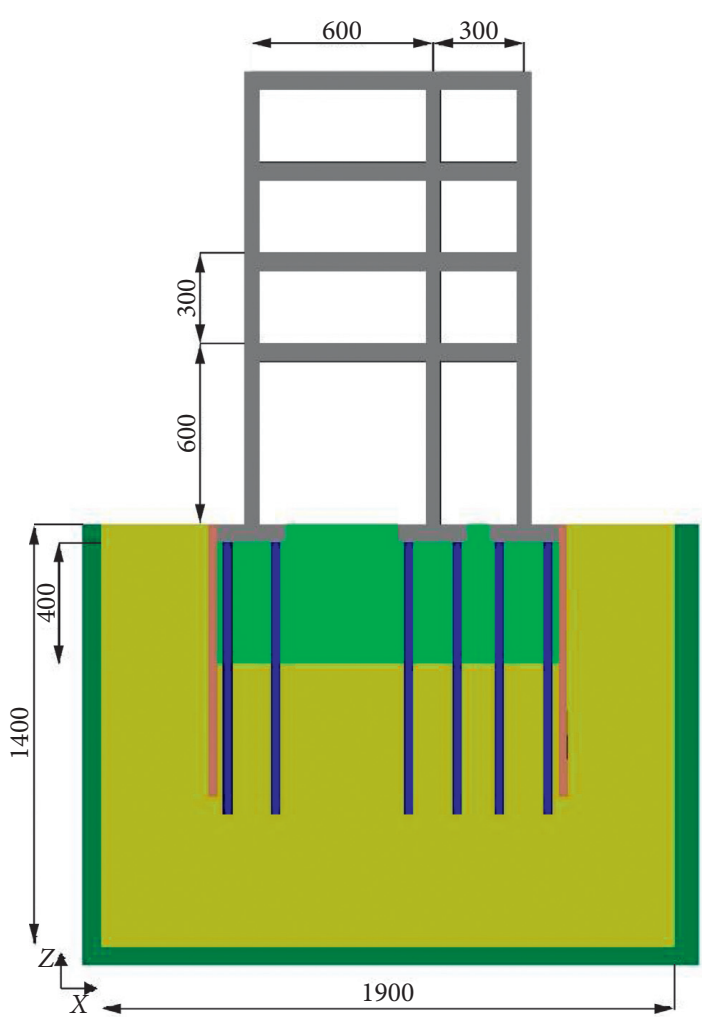

(a)

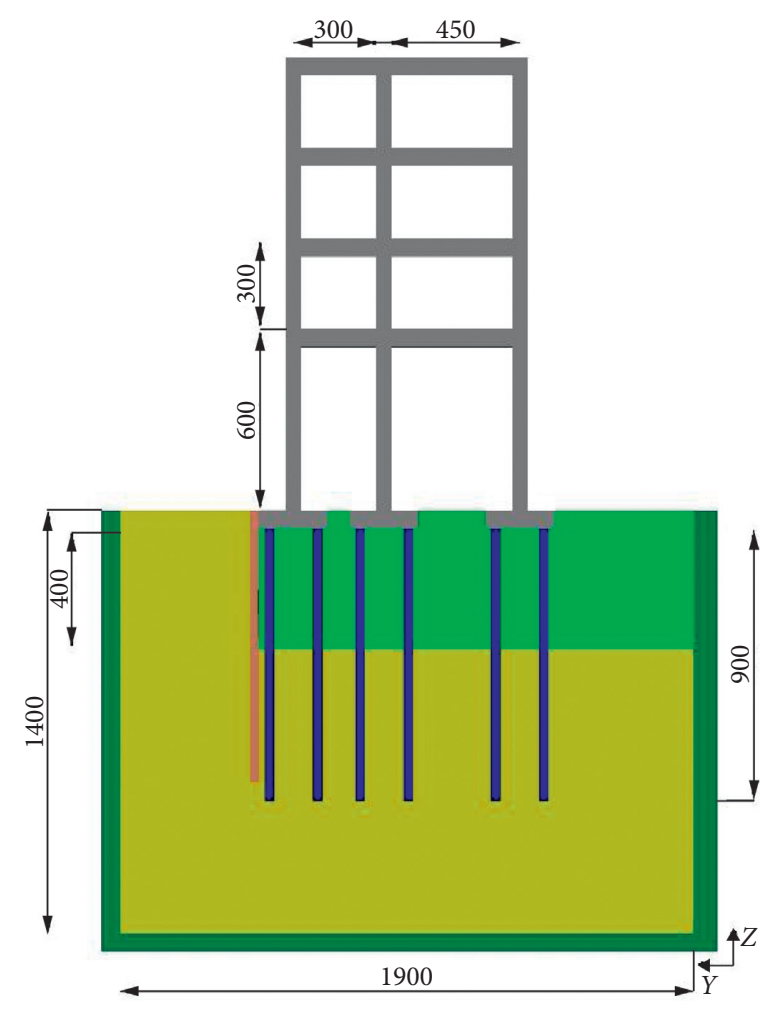

(b)

Figure 2: (a) Front view of model and (b) side view of model.
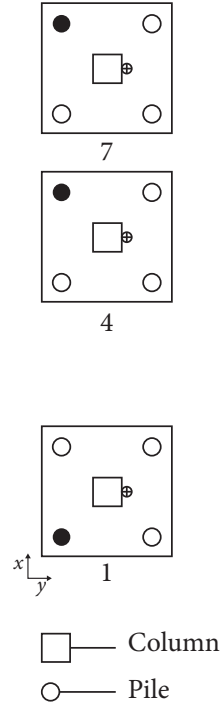
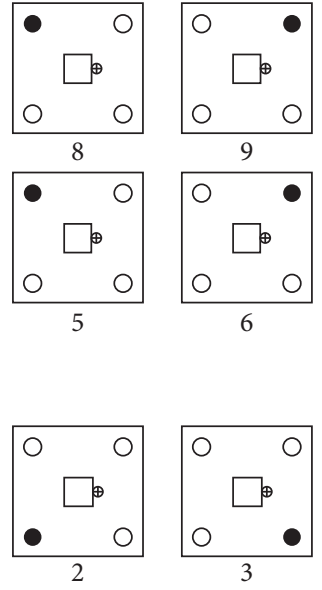

- Monitored pile Dial indicator

(a)
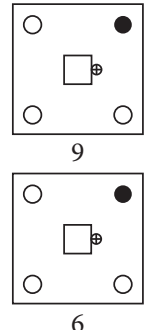

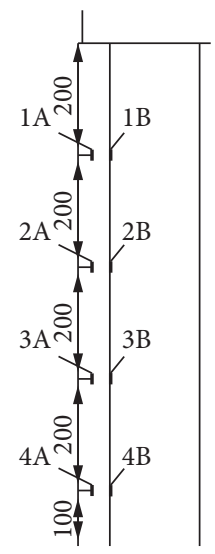

I Strain gauge

(b)
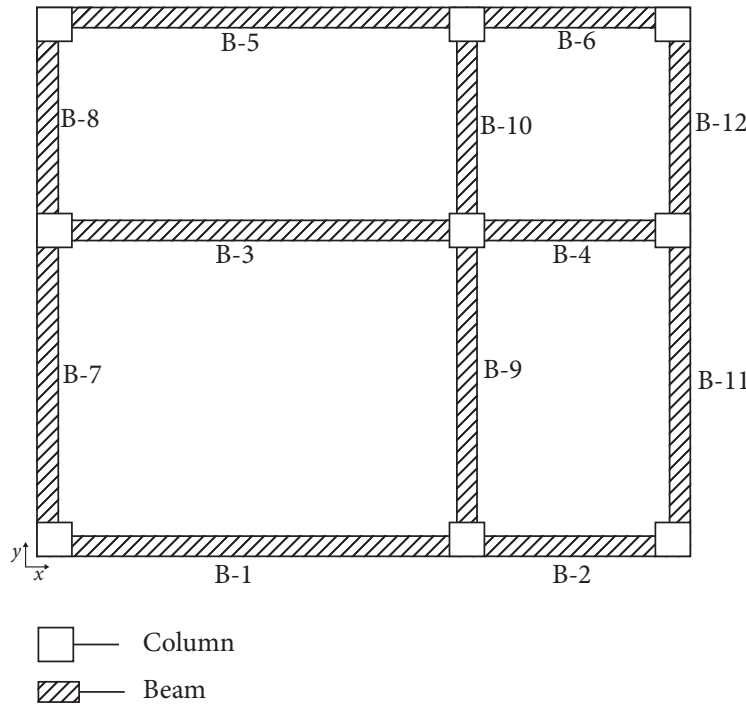

(c)

Figure 3: (a) Plan view of instrumentation setup, (b) strain gauges position layout of piles, and (c) number of beam layouts.

\section{Strain Changes and Displacements of Columns}

Strain gauges of columns were arranged at the midpoint of columns in the first layer. C1-1 meant that the strain gauge was on the midpoint of No. 1 column in the first layer. And the plus sign indicated axial tension, and the minus sign indicated axial compression.

Figure 7 showed strain changes of all columns during excavation except strain of C1-5, which was damaged during excavation. Based on monitoring strain data of columns, the following phenomena were discovered. (1) All strain values 
TABLE 3: Excavation sequence.

\begin{tabular}{lc}
\hline Step & Test content \\
\hline I & Install underpinning pile \\
II & Uplift the structure into the model box \\
III & Excavation of soil in Areas A and B after 2 hours \\
V & Excavation of soil in Areas 3 and C after 20 hours \\
VI & Excavation of soil in Areas 2, 6, and D after 25 hours \\
VII & Excavation of soil in Areas 1,5 , and 9 after 42 hours \\
VIII & Excavation of soil in Areas 4 and 8 after 49 hours \\
IX & Excavation of soil in Area 7 after 67 hours \\
X & Excavation of top half of the soil under spread footings after 73 hours \\
XI & Excavation of all soil under spread footings after 90 hours \\
\hline & Clean and compact the bottom of the excavation after 113 hours \\
\hline
\end{tabular}

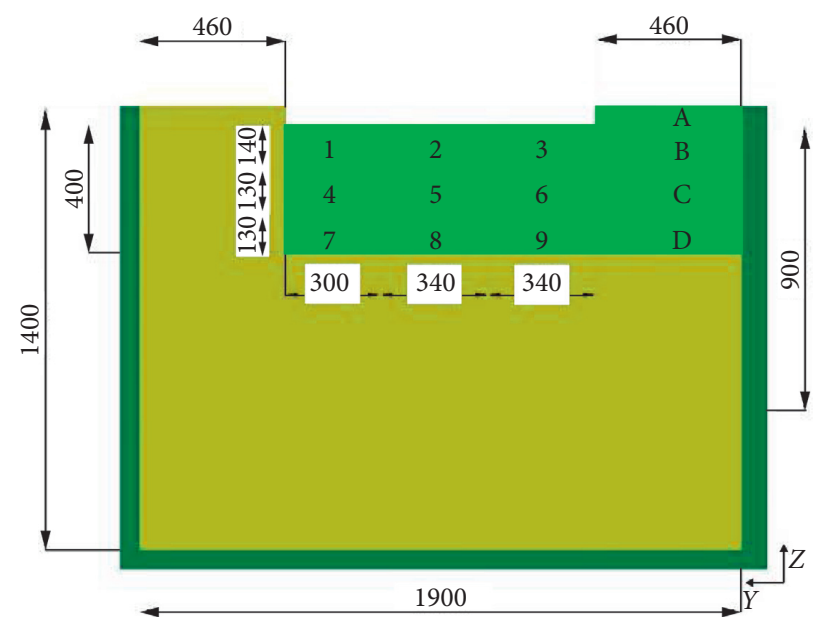

FIgURE 4: Number of excavation areas.

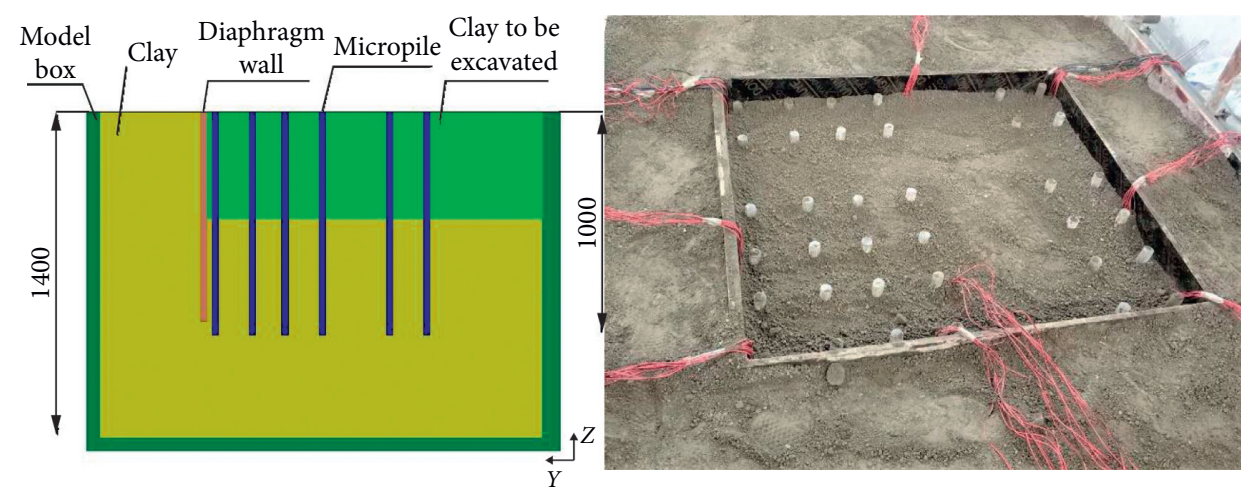

(a)

Figure 5: Continued. 


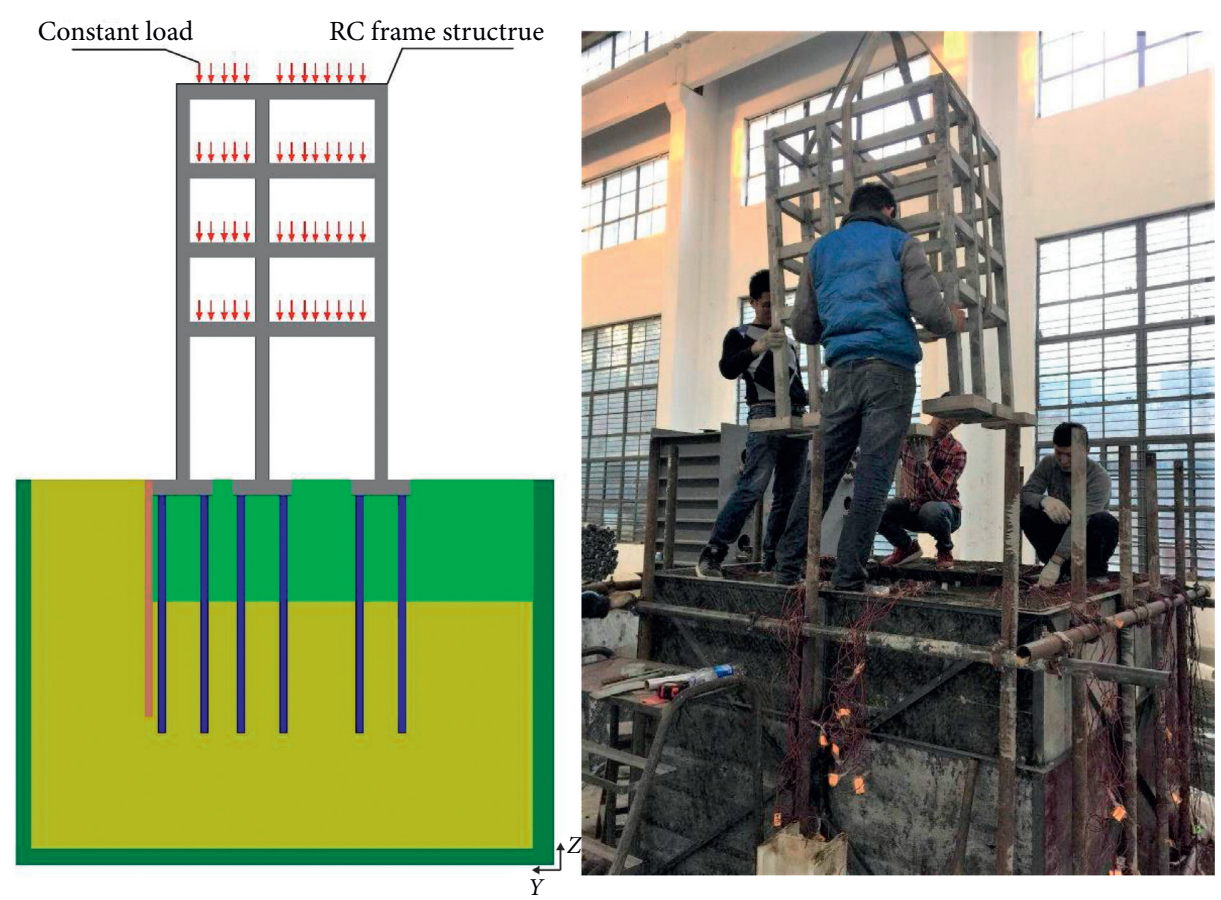

(b)

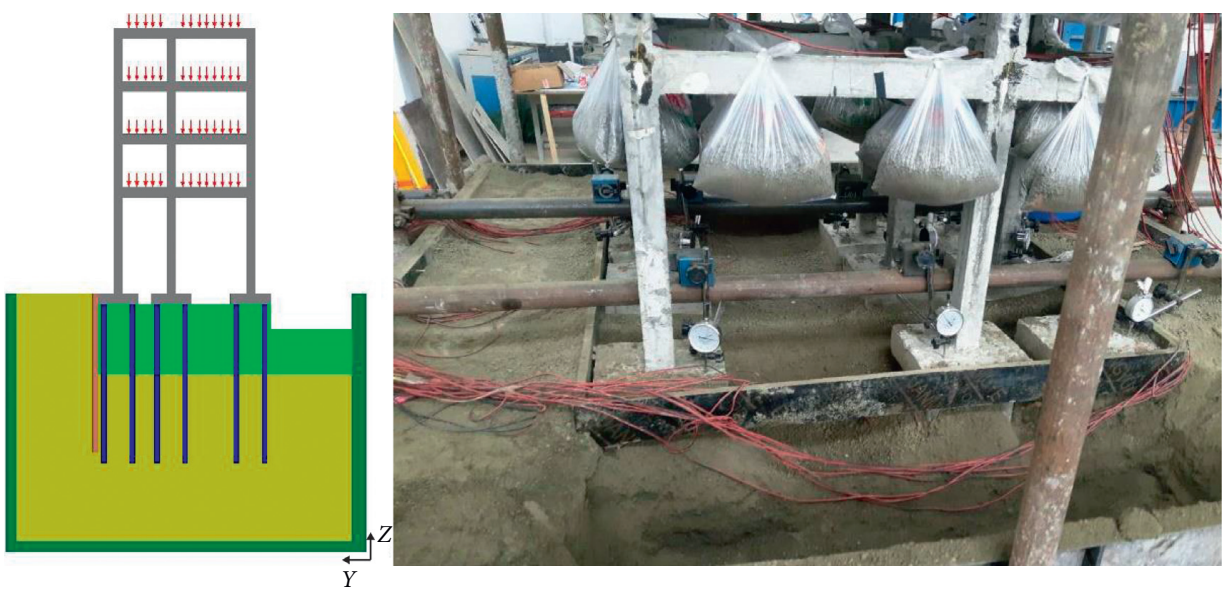

(c)

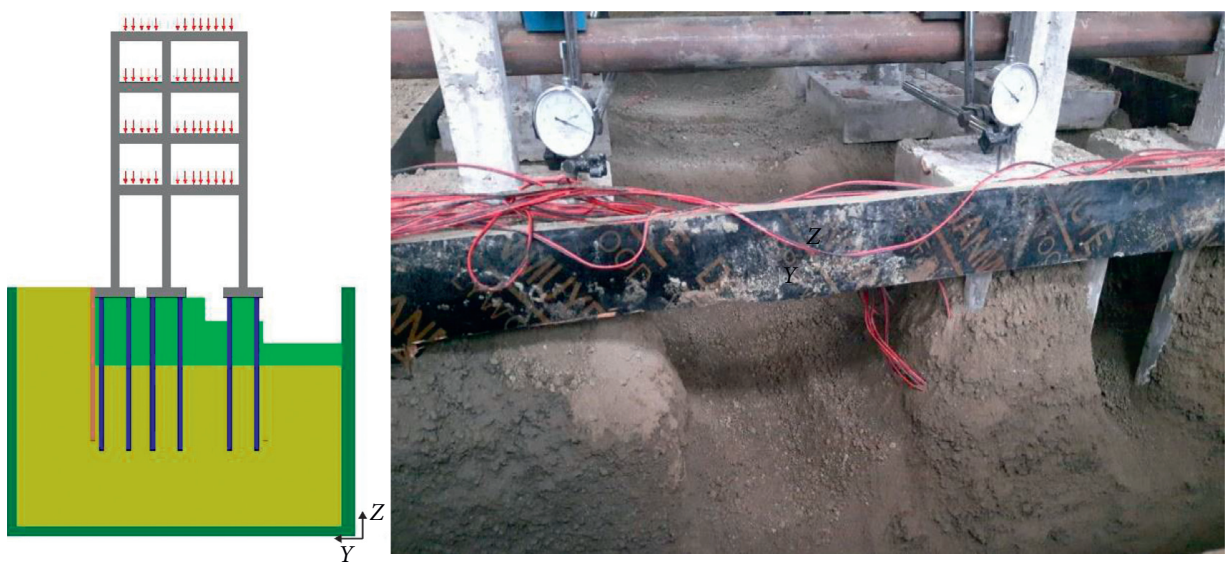

(d)

Figure 5: Continued. 


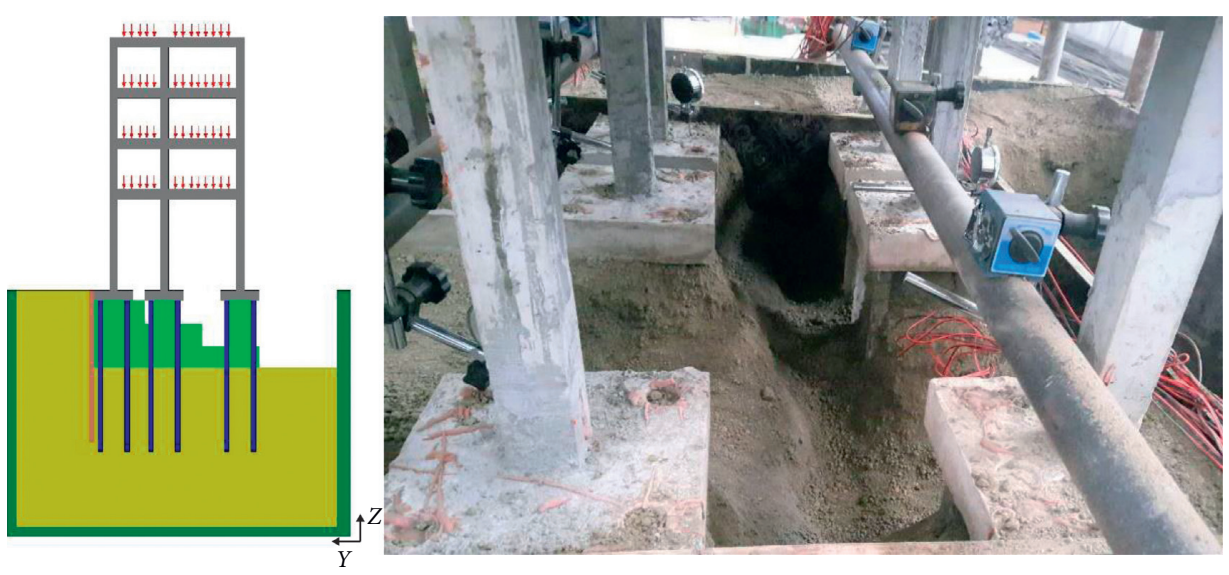

(e)

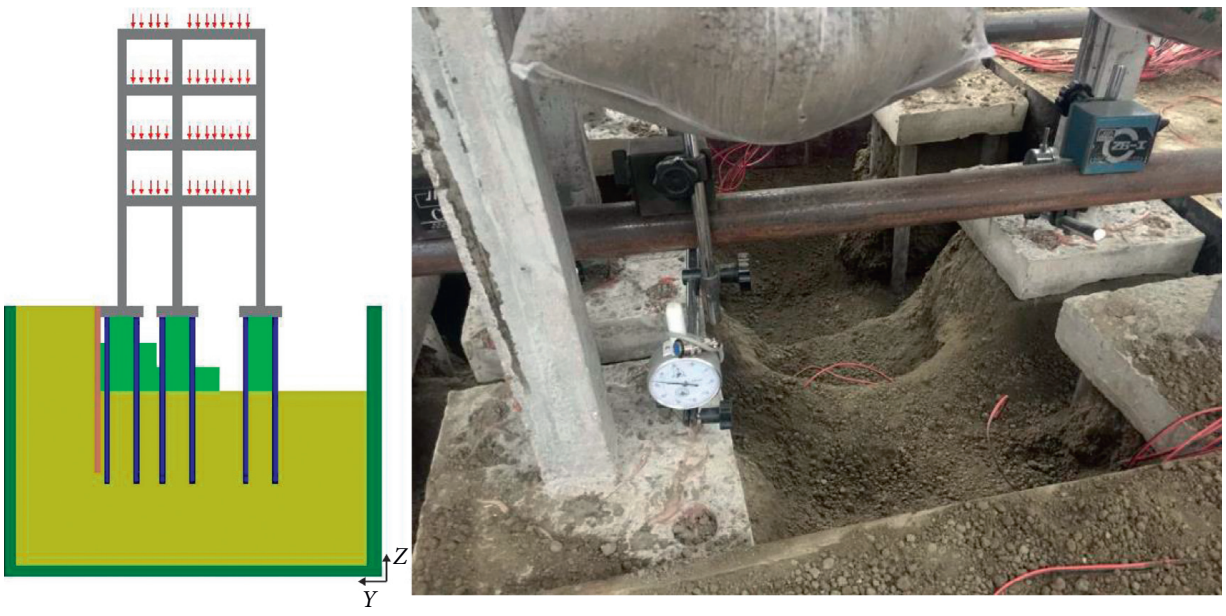

(f)

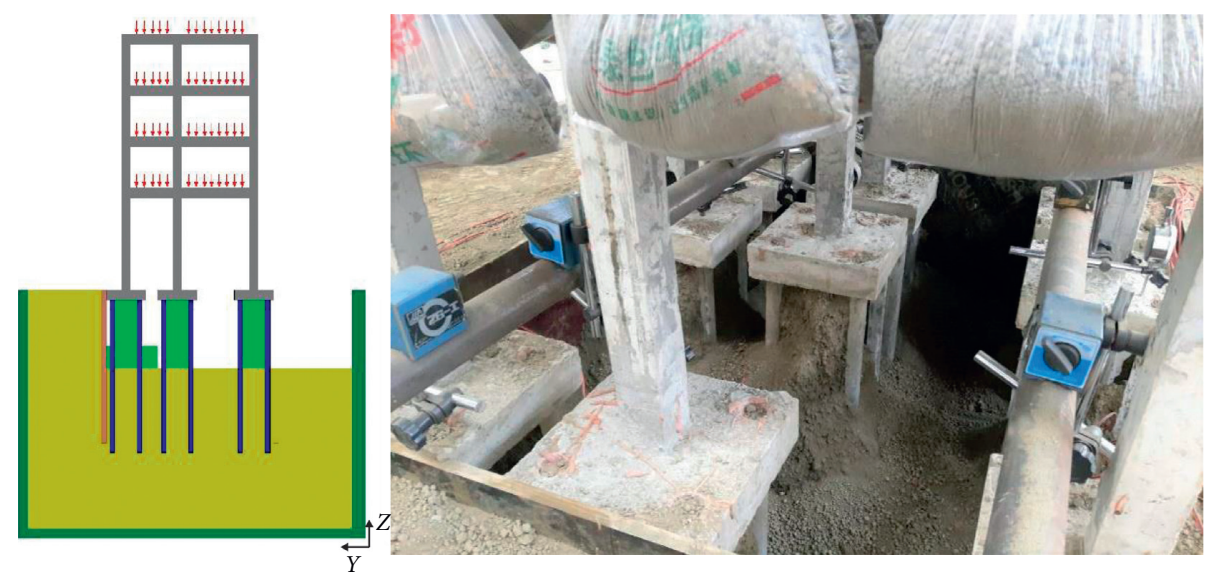

(g)

FIgURE 5: Continued. 


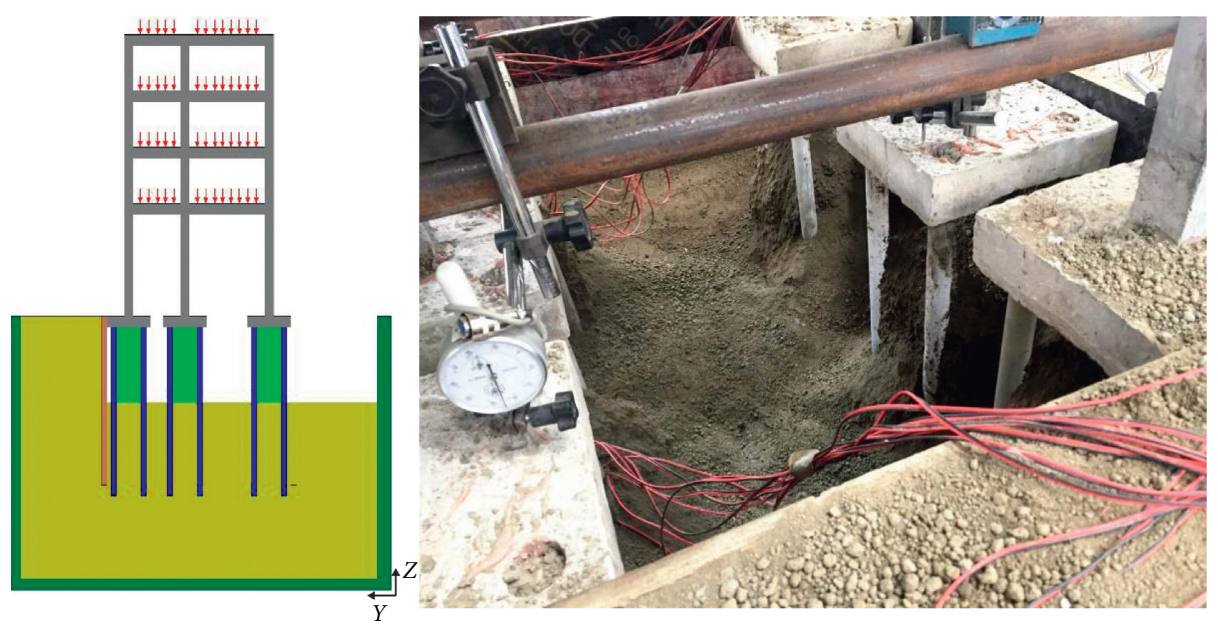

(h)

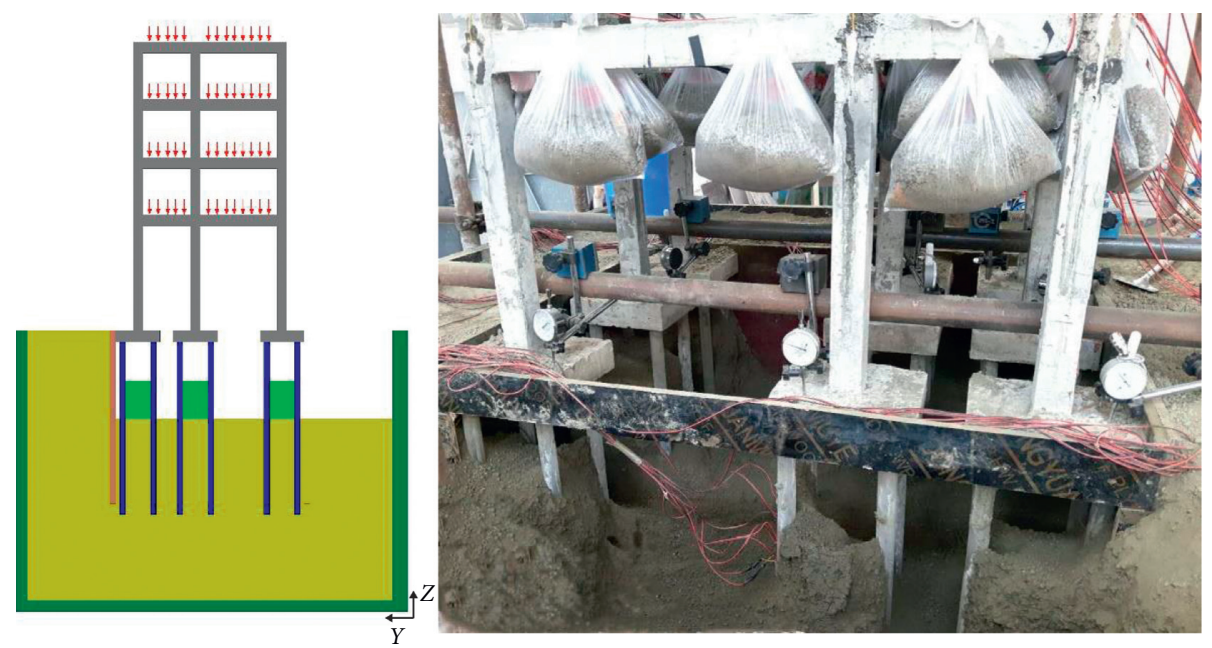

(i)

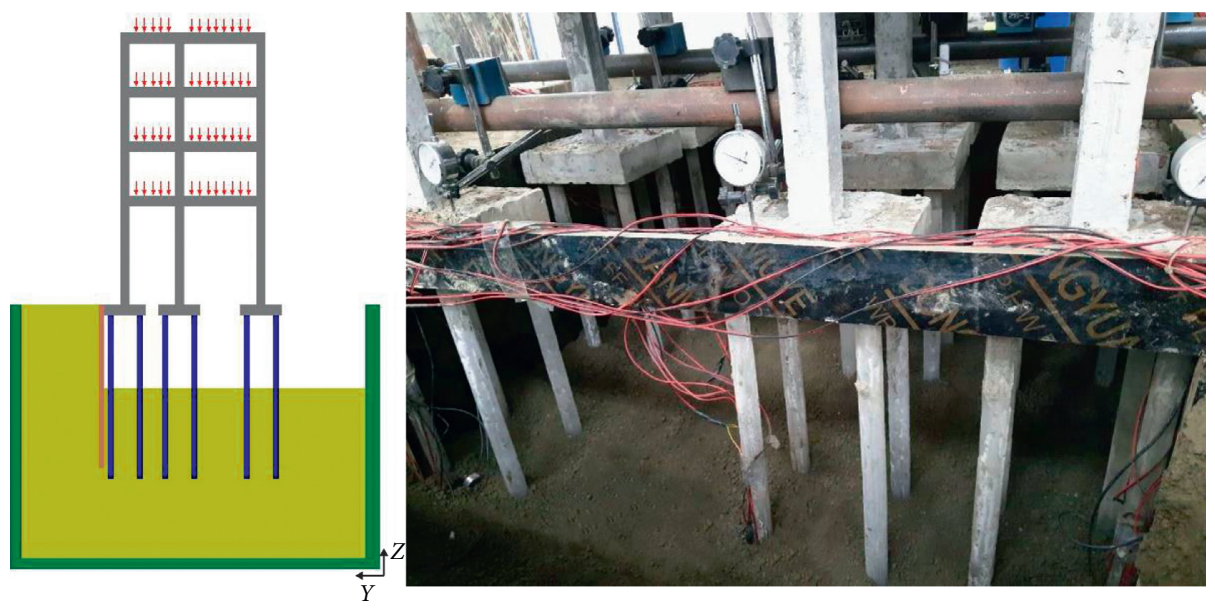

(j)

Figure 5: Model test setup.

of columns increased together after each stage. It illustrated that stresses of columns increased step by step and did not decrease after excavation. (2) Strain changes were the largest in Stage IX, because of the excavation under each spread footing. And strain changes of columns were very sensitive to excavation of soil under the foundation, partly due to the stress redistribution of the structure and the method of excavation from one side. (3) Strain changes of columns 


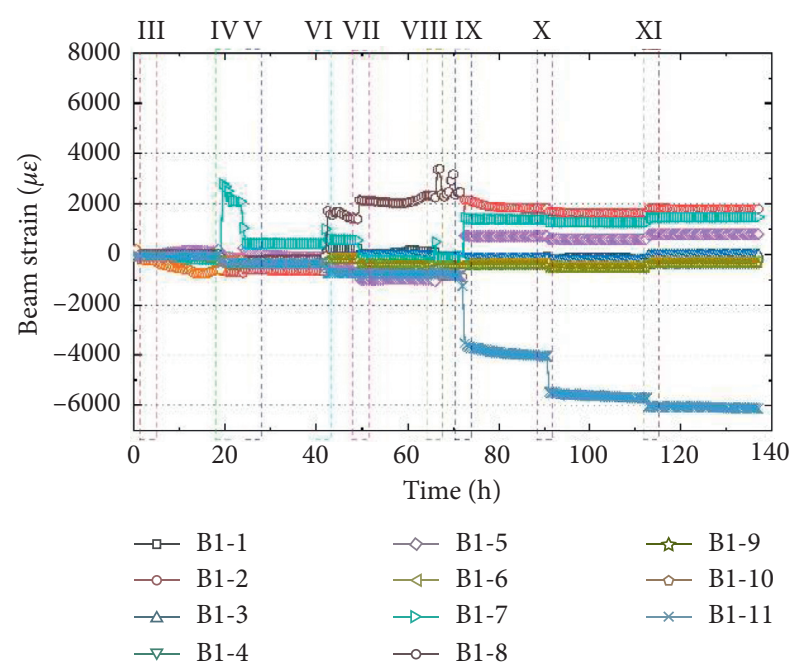

(a)

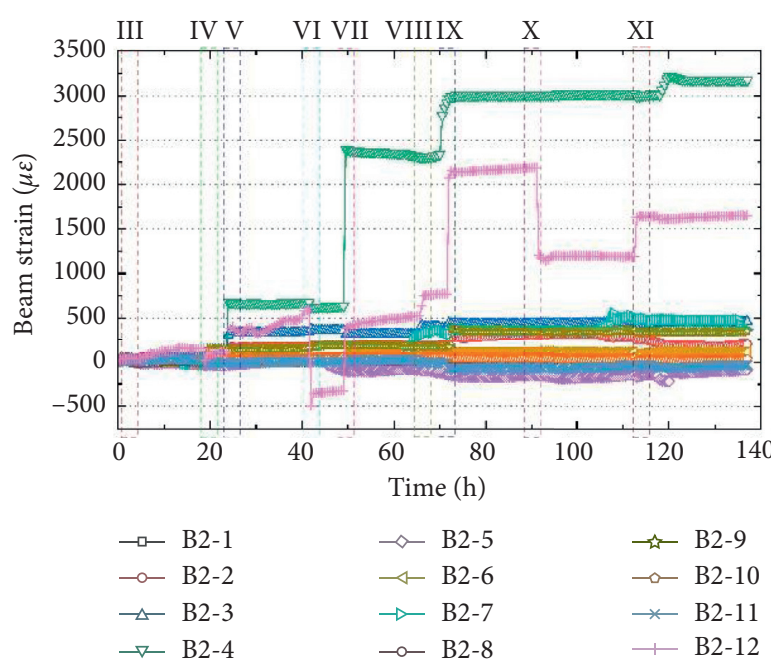

(b)

Figure 6: (a) Strain changes of beams in the first layer and (b) second layer.

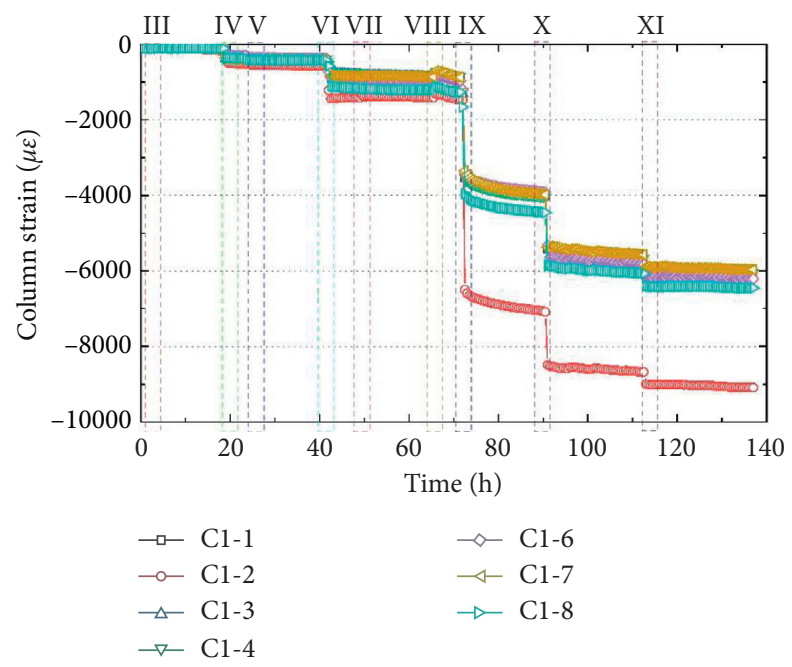

FIGURE 7: Strain changes of columns in the first layer.

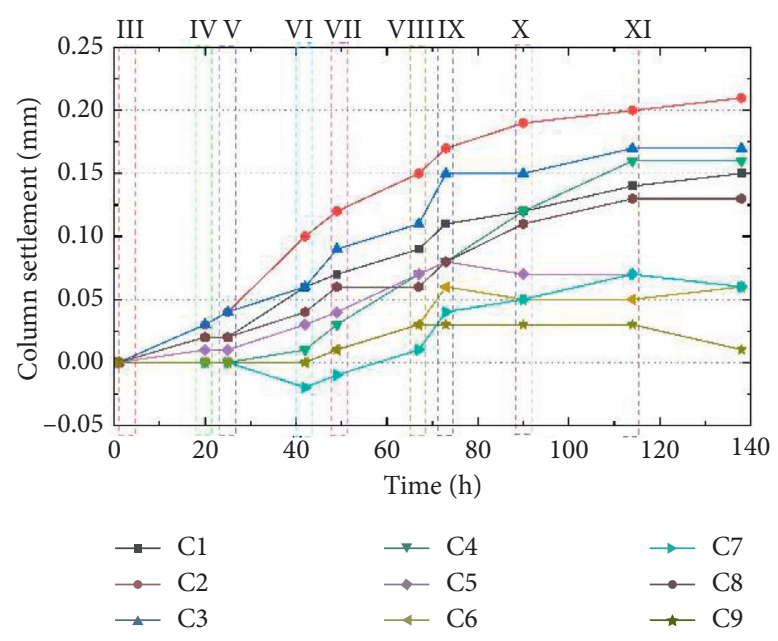

(a)

Figure 8: Continued. 


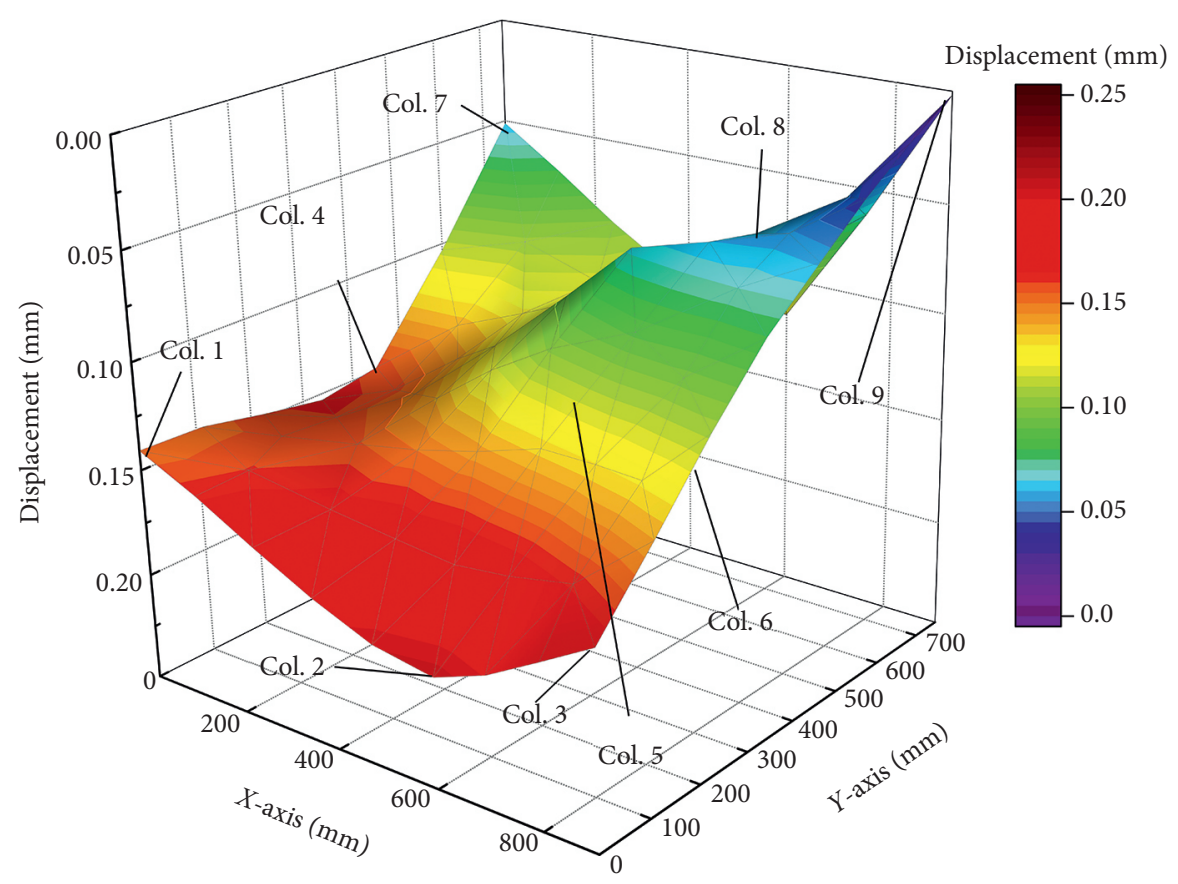

(b)

Figure 8: (a) Displacement of 9 columns and (b) 3D displacement of columns after 138 hours.

were lager in Stage VI, resulting from the excavation method and the stress redistribution of the structure. Finally, strain value of C1-2 was the largest during excavation, which need more attention in the future.

Figure 8 illustrated the displacement of 9 columns during excavation, and it should be noted that the positive value was settlement and the negative value was heave. In particular, C1 meant No. 1 column in the structure. The following rules were obtained from Figure 8(a). (1) Settlement of all columns was getting higher and higher during excavation. Only C7 experienced a little period of heave, partly due to stress unloading caused by excavation. Moreover, there were two reasons which caused the heave of C7. Firstly, the excavation from one side and the structure might tilt towards the excavation side. $\mathrm{C} 1, \mathrm{C} 2$, and $\mathrm{C} 3 \mathrm{had}$ higher settlement, but C7 and C9 had lower settlement. Secondly, based on FEM calculation, C7 had lower stress in the structure, resulting in the heave during excavation. C2 had the highest settlement during excavation, because C1C2 had the highest value of strain during excavation. (2) In Stage IX, settlement increments of all columns were the maximum due to the largest strain changes of all columns in this stage.

Figure 8(b) showed the final settlement of columns in a three-dimension way. Obviously, the structure had settled more on excavation side. Secondly, it can be seen that the front area was lower and the back area was higher, and the shape was like a typical step. Besides, the middle area was lower, and areas on both sides were higher. Mainly because soil was excavated from one side, and stresses of columns in front and middle areas were much higher. Tan and Wang made the similar conclusion [26, 27]: during excavation, the center portion of the excavation base would undergo much greater heave than the soils around the excavation perimeter.

\section{Strain Changes of Piles}

A lot of strain gauges were chosen to monitor the strain change of piles during excavation, reducing the accidental factors such as strain gauge error and damage. In this paper, at the same depth, strain gauges facing the excavation side are called Side A, and the opposite was Side B. For example, 2-1A meant that a strain gauge was in Position 1 of No. 2 pile, facing the excavation side. And the plus sign indicated the axial tension, and the minus sign indicated the axial compression. However, some strain gauges of piles were damaged during excavation, and they only had part of data or did not appear in figures below. The strain change of piles was shown in Figure 9.

Figure 9 showed strain changes of underpinning piles during excavation, and it was continuously monitored for 138 hours, which reflected the change of strain accurately and in time. In analysis of the strain in all piles, there were some regular phenomena during excavation. (1) In general, each excavation caused strain fluctuations of piles, especially in Stage IX, resulting in a largest change of strain. The main reason was that the soil under the foundation was excavated, and stresses from foundations transferred to piles gradually. Meanwhile, columns had the largest changes of strain in this stage. (2) Generally, from Stage III to Stage VII, the fluctuation of strain caused by excavation was the lowest in the test because the soil beneath the foundation still sustained most stress from the upper structure in these stages. Furthermore, a little part of stresses from foundations had 

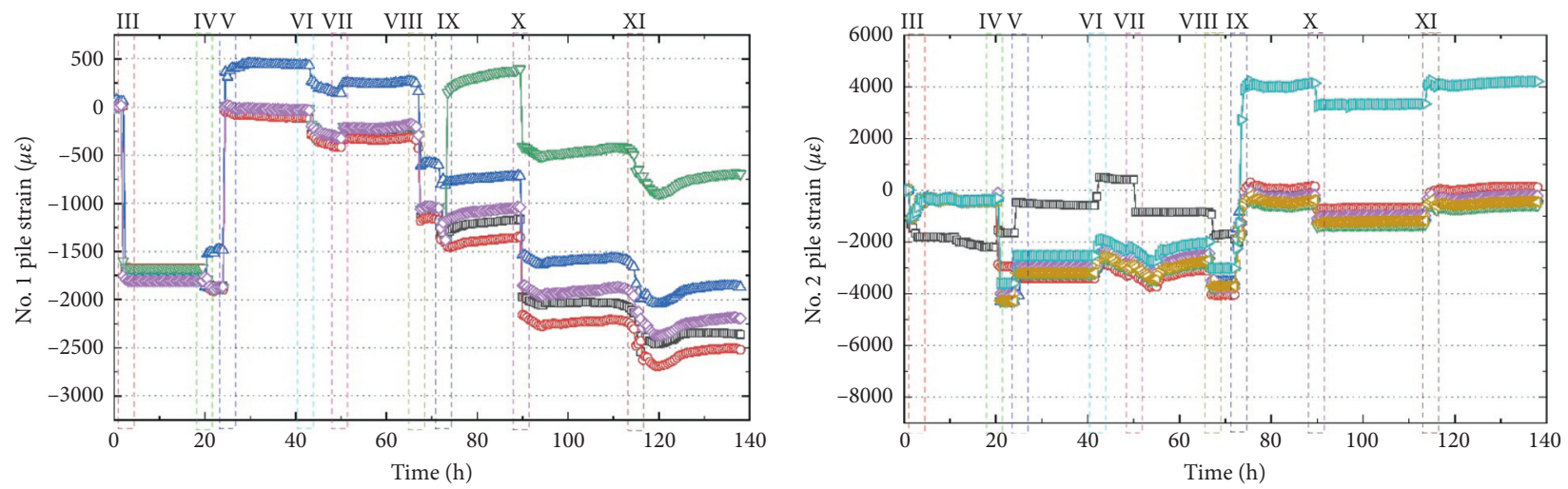

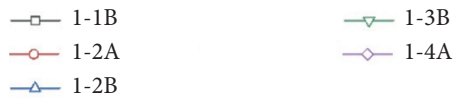

(a)

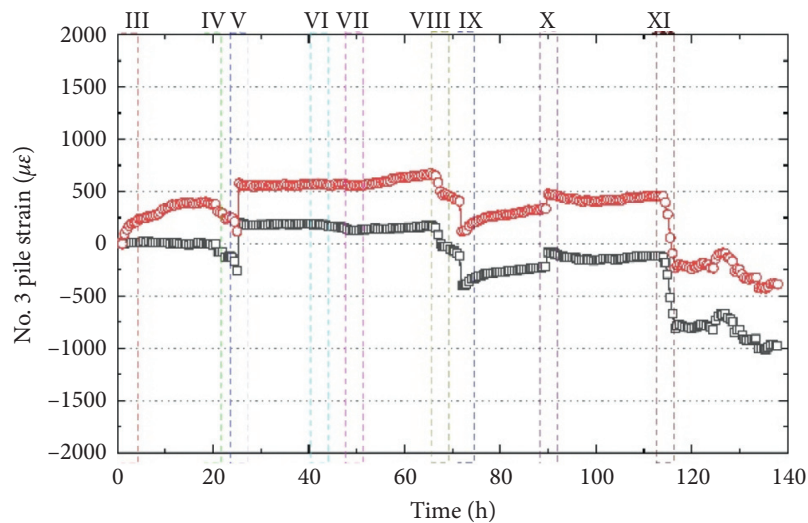

$\rightarrow-3-3 \mathrm{~B}$

$\multimap 3-4 \mathrm{~B}$

(c)

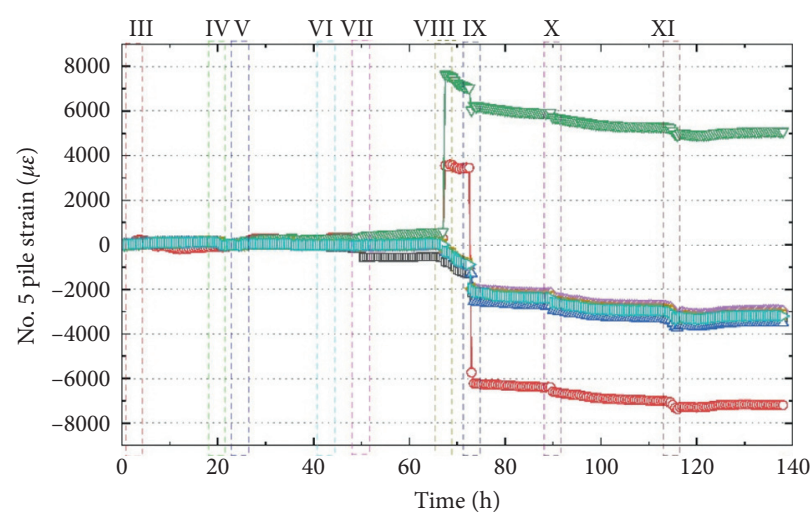

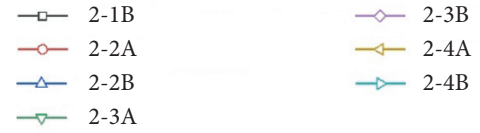

(b)
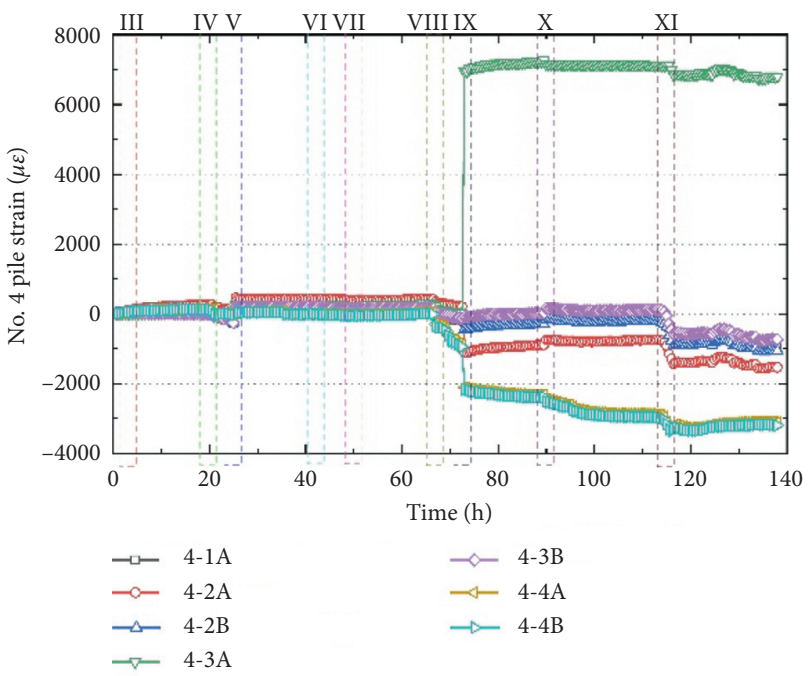

(d)
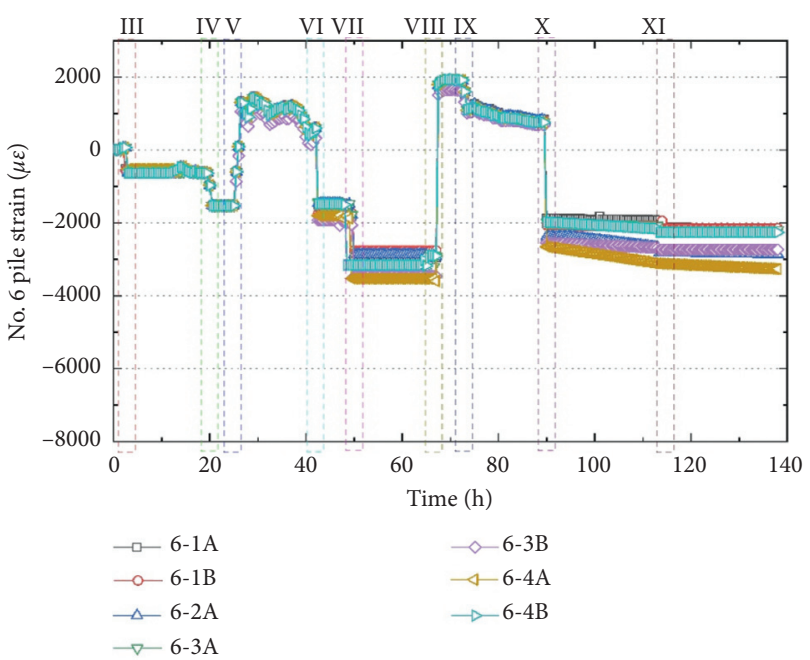

(f)

FIgURE 9: Continued. 


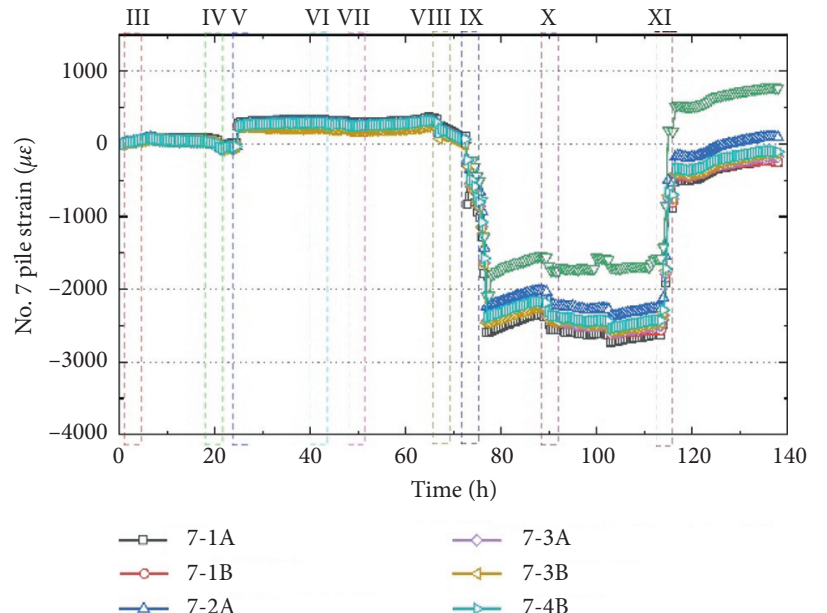

$\longrightarrow 7-2 \mathrm{~A}$

$\rightarrow-7-2 \mathrm{~B}$
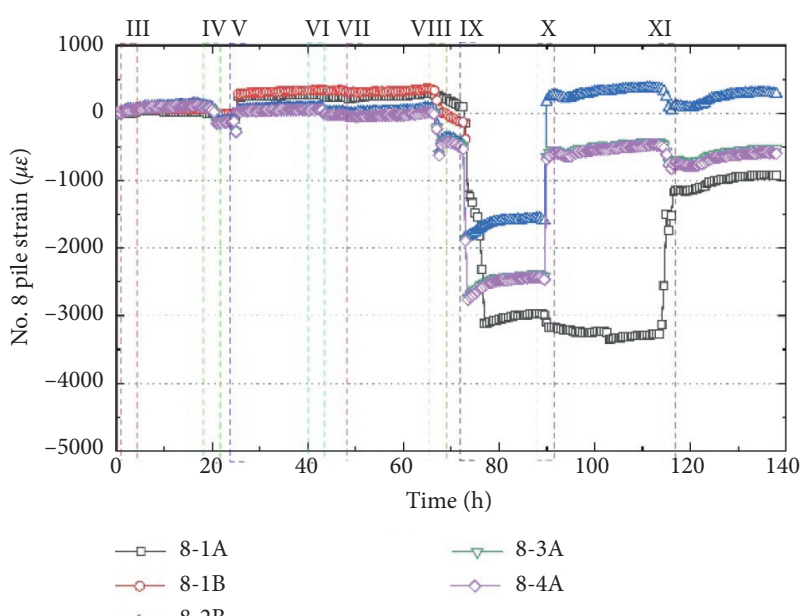

(h)

(g)

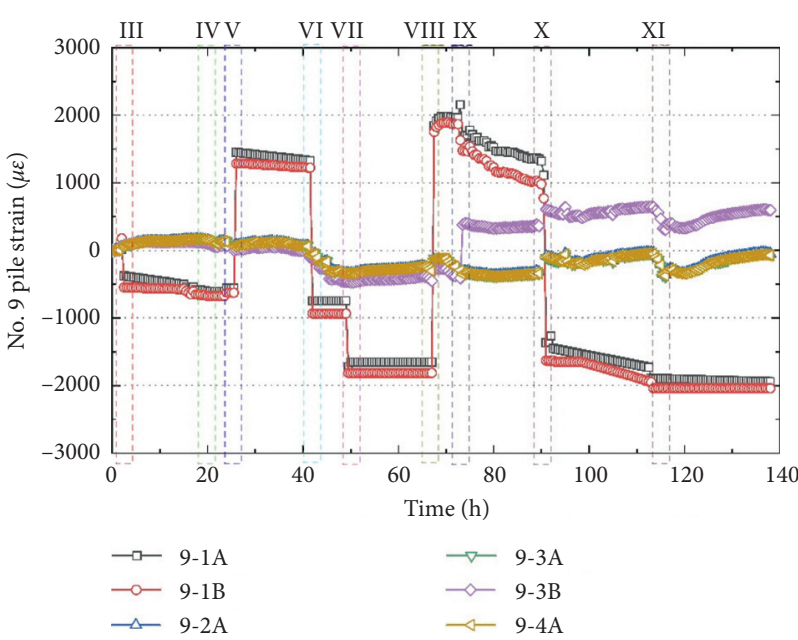

(i)

Figure 9: Strain changes of 9 piles.

already transferred to underpinning piles in Stage II, which were not monitored at first. However, No. 1 pile, No. 2 pile, and No.6 pile were exceptions. It might be related to the way of excavation from one side or related to error of strain. And it required more research in the future. (3) In Stage XI, strain of piles fluctuated without excavation, due to the factor of cleaning and compacting the soil.

\section{Conclusion}

This paper presented the impacts of underground excavation on a preexisting building based on a scale model test with a special excavation method, of which soil was excavated from one side. The main findings in this test were summarized as follows:

(1) In general, strain changes of beams were the lowest, and strain changes of piles were the largest during excavation. And strain values of columns were getting higher and higher during excavation. Therefore, much more attention should be paid for underpinning piles and columns in the first layer. In engineering practice, before underpinning and excavation, all columns in the first layer needed to be checked and strengthened, and a few beams also needed to be checked and strengthened, in case of stresses redistribution and concentration during excavation. In addition, high-strength precast piles were acquired as underpinning piles because they can sustain complex strain changes in poor excavation condition. Furthermore, for the design of underpinning piles, based on large strain changes of piles during excavation in this test, it was very far from enough to design underpinning piles only considering the bearing capacity.

(2) The excavation of soil under foundations had a great influence on the stability of the structure, which made the largest strain changes in beams, columns, and piles. This process seemed to be unavoidable; therefore, some strategies were considered as follows. First, excavation duration should be extended to avoid large 
increments of strain in short time. Second, soil under foundations could be divided into smaller blocks and excavated them in order. Finally, monitoring of this excavation state should be strengthened.

(3) Excavation method was of huge impact on settlement of the structure. After excavation, all columns had settled in the end, and the shape of the settlement in three-dimensional way was like a typical step. Settlement on the excavation side was higher than that on the other side. This excavation method need not destroy the first floor of the preexisting building before excavation, but it caused more settlement on excavation side; furthermore, it would aggravate uneven settlement and inclination of the preexisting structure.

\section{Data Availability}

The data used to support the findings of this study are available from the corresponding author upon request.

\section{Conflicts of Interest}

The authors declare that they have no conflicts of interest.

\section{Acknowledgments}

The authors are grateful to the financial support from Xihua University.

\section{References}

[1] R. Z. Kordahi, Underpinning Strategies for Buildings with Deep Foundations, Massachusetts Institute of Technology, Cambridge, MA, USA, 2004

[2] K. Satô, T. Hanamura, K. Sanbongi et al., "Underground space use in Japan," Civil Engineering in Japan, vol. 10-27, 1990.

[3] Y. Masuda, T. Minoshima, and H. Makino, "Large-scale underpinning for an underground urban railway station," Tunnelling and Underground Space Technology, vol. 7, no. 2, pp. 133-140, 1992.

[4] Y. Iwasaki, H. Watanabe, M. Fukuda, A. Hirata, and Y. Hori, "Construction control for underpinning piles and their behaviour," Géotechnique, vol. 44, no. 4, pp. 681-689, 1994.

[5] J. R. Davie and H. Senapathy, "Underpinning a 3000-ton structure with high-capacity mini-piles," in Proceeding of the Deep Foundations 2002: An International Perspective on Theory, Design, Construction, and Performance, pp. 647-654, Orlando, Florida, February 2002.

[6] Y.-H. Park, J.-P. Kim, and K.-H. Cho, "Stability analysis of subway box structure supported by modified underpinning method," Tunnelling and Underground Space Technology, vol. 50, pp. 199-208, 2015.

[7] A. Chepurnova, "Assessing the influence of jet-grouting underpinning on the nearby buildings," Journal of Rock Mechanics and Geotechnical Engineering, vol. 6, no. 2, pp. 105-112, 2014.

[8] S. Horpibulsuk, A. Kumpala, and W. Katkan, "A case history on underpinning for a distressed building on hard residual soil underneath non-uniform loose sand," Soils and Foundations, vol. 48, no. 2, pp. 267-285, 2008.
[9] A. Pinto, S. Ferreira, and V. Barros, "Underpinning solutions of historical constructions," in Proceedings of the Third International Congress on Construction History, pp. 1003-1012, Cottbus, Germany, May 2001.

[10] A. T. C. Goh, W. G. Zhang, and K. S. Wong, "Deterministic and reliability analysis of basal heave stability for excavation in spatial variable soils," Computers and Geotechnics, vol. 108, pp. 152-160, 2019.

[11] J. Li, X. Xie, Q. Zhang et al., "Distress evaluation and remediation for a high-rise building with pile-raft foundation," Journal of Performance of Constructed Facilities, vol. 28, Article ID 04014005, 2013.

[12] S. Ye, J. Han, and G. Ye, Soil Improvement and Underpinning Technologies, Chinese Architecture and Building Press, Beijing, China, 1994.

[13] L. Yan, G. Wang, M. Chen et al., "Experimental and application study on underpinning engineering of bridge pile foundation," Advances in Civil Engineering, vol. 2018, Article ID 5758325, 13 pages, 2018.

[14] R. Zhang, W. Zhang, and A. T. C. Goh, "Numerical investigation of pile responses caused by adjacent braced excavation in soft clays," International Journal of Geotechnical Engineering, vol. 1-15, 2018.

[15] J. Han and S.-L. Ye, "A field study on the behavior of a foundation underpinned by micropiles," Canadian Geotechnical Journal, vol. 43, no. 1, pp. 30-42, 2006.

[16] J. Han and S.-L. Ye, "A field study on the behavior of micropiles in clay under compression or tension," Canadian Geotechnical Journal, vol. 43, no. 1, pp. 19-29, 2006.

[17] H.-f. Shan, F. Yu, T.-d. Xia et al., "Performance of the underpinning piles for basement-supplementing retrofit of a constructed building," Journal of Performance of Constructed Facilities, vol. 31, Article ID 04017017, 2017.

[18] S. J. Boone, "Ground-movement-related building damage," Journal of Geotechnical Engineering, vol. 122, no. 11, pp. 886-896, 1996.

[19] M. D. Boscardin and E. J. Cording, "Building response to excavation-induced settlement," Journal of Geotechnical Engineering, vol. 115, no. 1, pp. 1-21, 1989.

[20] Y. Tan, R. Huang, Z. Kang et al., "Covered semi-top-down excavation of subway station surrounded by closely spaced buildings in downtown Shanghai: building response," Journal of Performance of Constructed Facilities, vol. 30, Article ID 04016040, 2016.

[21] F. Chen, L. Wang, and W. Zhang, "Reliability assessment on stability of tunnelling perpendicularly beneath an existing tunnel considering spatial variabilities of rock mass properties," Tunnelling and Underground Space Technology, vol. 88, pp. 276-289, 2019.

[22] M. Makarchian and H. G. Poulos, "Simplified method for design of underpinning piles," Journal of Geotechnical Engineering, vol. 122, no. 9, pp. 745-751, 1996.

[23] F. Tatsuoka and O. Haibara, "Shear resistance between sand and smooth or lubricated surfaces," Soils and Foundations, vol. 25, no. 1, pp. 89-98, 1985.

[24] F. Tatsuoka, F. Molenkamp, T. Torii, and T. Hino, "Behavior of lubrication layers of platens in element tests," Soils and Foundations, vol. 24, no. 1, pp. 113-128, 1984.

[25] C.-Y. Ou, P.-G. Hsieh, and D.-C. Chiou, "Characteristics of ground surface settlement during excavation," Canadian Geotechnical Journal, vol. 30, no. 5, pp. 758-767, 1993.

[26] Y. Tan and D. Wang, "Characteristics of a large-scale deep foundation pit excavated by the central-island technique in 
Shanghai soft clay. I: bottom-up construction of the central cylindrical shaft," Journal of Geotechnical and Geoenvironmental Engineering, vol. 139, no. 11, pp. 1875-1893, 2013.

[27] Y. Tan and D. Wang, "Characteristics of a large-scale deep foundation pit excavated by the central-island technique in Shanghai soft clay. II: top-down construction of the peripheral rectangular pit," Journal of Geotechnical and Geoenvironmental Engineering, vol. 139, no. 11, pp. 1894-1910, 2013. 